\title{
Changes of Amino Acids Composition and Relative Digestibility of Lysozyme in the Reaction with $\alpha$-Dicarbonyl Compounds in Aqueous System
}

\author{
Hiromichi KATO, ${ }^{1}$ Nguyen van CHUYEN, ${ }^{2}$ Nobuko UtsunOMiYA, ${ }^{3}$ \\ and Akihiro OKITANI ${ }^{4}$ \\ ${ }^{1}$ Department of Agricultural Chemistry, The University of \\ Tokyo, Bunkyo-ku, Tokyo 113, Japan \\ ${ }^{2}$ Laboratory of Food and Nutritional Science, Obirin \\ Junior College, Machida, Tokyo 194, Japan \\ ${ }^{3}$ Department of Food Science, Kyoritsu Women's \\ University, Chiyoda-ku, Tokyo 101, Japan \\ ${ }^{4}$ Laboratory of Food Chemistry, Nippon \\ Veterinary and Zootechnical College, \\ Musashino, Tokyo 180, Japan
}

(Received June 26, 1985)

\begin{abstract}
Summary Lysozyme was reacted with xylose, methyl linoleate, glyoxal, methylglyoxal and diacetyl in an aqueous system $\left(50^{\circ} \mathrm{C}, \mathrm{pH} 6.0\right)$, and browning, polymerization, changes of amino acids composition and relative digestibility of the browned lysozyme were investigated. Browning intensity as well as degree of polymerization of lysozyme in the reaction with $\alpha$-dicarbonyls was higher than with xylose or methyl linoleate. After 10 days of reaction with $\alpha$-dicarbonyls, the amino acid composition of lysozyme was markedly affected; i.e., $30-70 \%$ of lysine, $40-50 \%$ of tryptophan and $90 \%$ of arginine were lost respectively. By digestion with a pepsin-pancreatin system, it was observed that the relative digestibility of lysozyme reacted with dicarbonyl was lower than that of lysozyme reacted with methyl linoleate or xylose.
\end{abstract}

Key Words lysozyme, glyoxal, methylglyoxal, diacetyl, xylose, methyl linoleate, relative digestibility, amino acids (change of), polymerization

$\alpha$-Dicarbonyl compounds are known to be products of the degradation of carbohydrates $(1,2)$ and fatty acids $(3,4)$. Hitherto, many studies have been carried out on the reactions of protein with carbohydrate, lipid or fatty acids. Some research has been done on the reactions of $\alpha$-dicarbonyl compounds with amino acids $(5-7)$ and peptides $(8,9)$. However, few studies have been carried out on the

\footnotetext{
${ }^{1}$ 加藤博通, ${ }^{2}$ グュエン・ヴァン・チュエン, ${ }^{3}$ 宇都宮信子, ${ }^{4}$ 沖谷明紘
} 
reaction of $\alpha$-dicarbonyl compounds with protein.

$\mathrm{We}(10 a)$ recently studied the mechanism of modification of lysozyme by reaction with glucose in the dry state, and suggested that $\alpha$-dicarbonyl compounds derived from glucose play an important role in the polymerization of lysozyme.

Subsequently, we demonstrated the polymerization of lysozyme in the dry state caused by several $\alpha$-dicarbonyl compounds known to be derived from reducing sugars through the amino-carbonyl reaction $(10 b)$.

The present paper deals with the reaction of lysozyme with some $\alpha$-dicarbonyl compounds as well as methyl linoleate and D-xylose in an aqueous system i.e., chemical changes of lysozyme and its relative digestibility from the nutritional point of view in vitro. The results show that the $\alpha$-dicarbonyl compounds tested polymerize lysozyme also in aqueous system.

\section{MATERIALS AND METHODS}

Chemicals. Lysozyme (egg white, $6 \times$ crystallized) was purchased from Seikagaku Kogyo Co., Ltd. Diacetyl and glyoxal (40\% solution) were obtained from Wako Pure Chemicals Industries, Ltd. Methylglyoxal (40\% solution) and methyl linoleate were purchased from Nakarai Chemicals, Ltd. D-Xylose was obtained from Kanto Chemicals, Co., Inc. Diacetyl, glyoxal and methylglyoxal were used in this experiment without further purification. Pepsin (porcine stomach mucosa) and pancreatin (porcine pancreas) were obtained from Sigma Chemical, Co. All other reagents are guaranteed chemicals.

Reaction conditions and preparation procedure for browned lysozyme samples. Lysozyme $(0.7 \mathrm{mmol})$ and carbonyl compound $(35 \mathrm{mmol})$ were dissolved in $200 \mathrm{ml}$ of $0.1 \mathrm{M}$ phosphate buffer $(\mathrm{pH} 6.0)$ and incubated at $50^{\circ} \mathrm{C}$. The sampling was carried out after 1,5 and 10 days of incubation. The reaction solutions $(200 \mathrm{ml})$ were then washed with diethyl ether $(300 \mathrm{ml}) 3$ times and lyophilized to gain the crude browned lysozyme powder. This powder was suspended again in diethyl ether with stirring and washed successively at $5^{\circ} \mathrm{C}$ to remove completely the remaining dicarbonyl compounds, 2,4-dinitrophenylhydrazine reagent being used to confirm that no carbonyl remained. After being thoroughly washed, diethyl ether in the browned lysozyme powder was eliminated by sucking with an aspirator at room temperature. The browned lysozyme powder was stored at $5^{\circ} \mathrm{C}$ before use. In the case of the lysozyme-xylose reaction, the remaining xylose was removed by dialyzing the incubated mixture against water for 3 days. Methyl linoleate was reacted with lysozyme by continuous stirring under the same conditions as those of other carbonyls.

Measurement of browning intensity. Browning intensity of the reaction solutions of lysozyme with carbonyl compounds was measured at $500 \mathrm{~nm}$ with a Shimadzu double beam Spectrophotometer UV-180. The browned reaction solutions were transparent without precipitation after 10 days of reaction. Carbonyl solutions at zero time were used as references. 


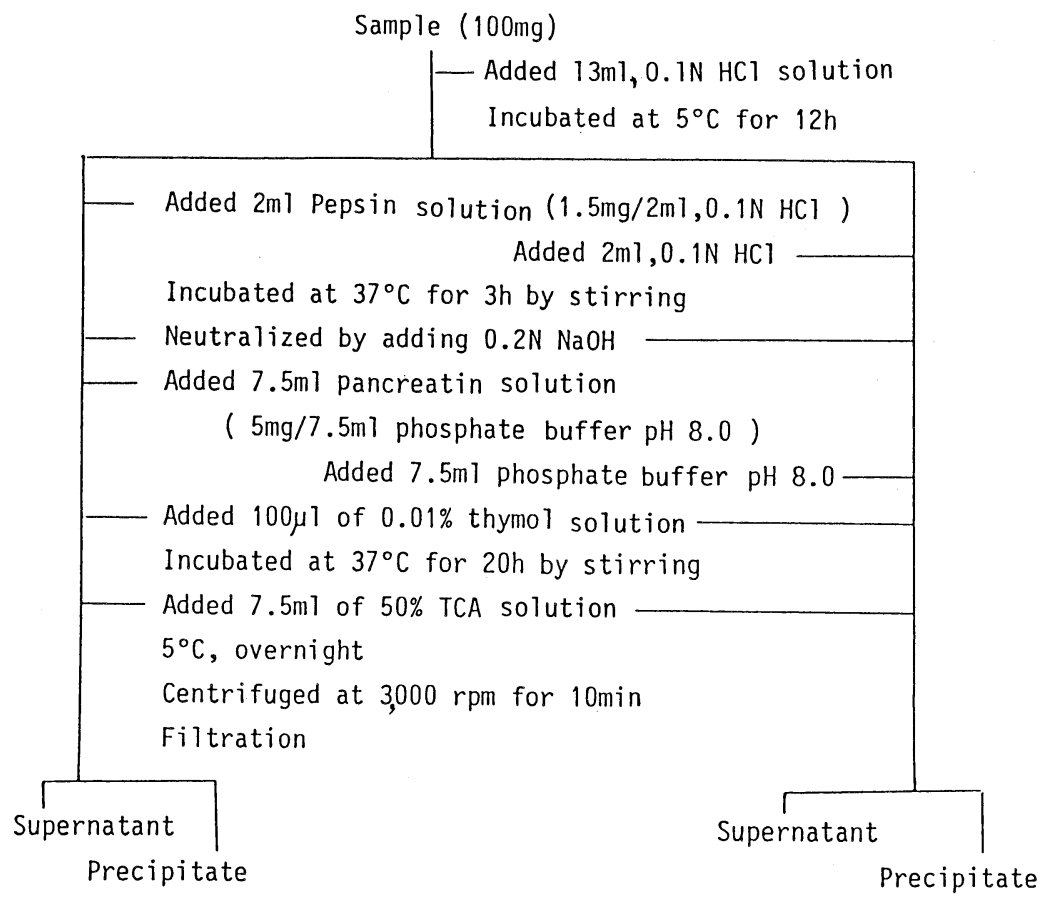

Fig. 1. Procedure for the digestion process of browned lysozyme in vitro.

SDS polyacrylamide gel electrophoresis. SDS polyacrylamide gel electrophoresis was carried out according to the method of Weber and Osborn (11) with slab gel solutions containing $10 \%$ 2-mercaptoethanol, and the electrophoresis was performed at $0.6 \mathrm{~mA}$ for $3 \mathrm{~h}$. Coomassie brilliant blue R-250 solution $(0.1 \%)$ was used for staining. The relative amounts of monomer and oligomers of lysozyme were calculated from the absorbance at $565 \mathrm{~nm}$ of the corresponding stained protein bands using a Toyo DMU-33C Densitometer.

Amino acid analysis. The dialyzed browned lysozyme powder (1 mg) was hydrolyzed by $6 \mathrm{~N} \mathrm{HCl}$ at $110^{\circ} \mathrm{C}$ for $24 \mathrm{~h}$. After hydrolysis, $\mathrm{HCl}$ was completely removed under a vacuum, amino acid hydrolysis then being carried out with a Hitachi Amino Acid Analyzer 835. Tryptophan was determined by the method of Matsubara and Sasaki(12).

Incubation procedure for the measurement of relative digestibility. In order to measure the relative digestibility of browned lysozyme, the product was digested by the method of Matoba et al.(13) with some modifications as shown in Fig. 1. The relative digestibility (R. D.) was calculated as follows:

$$
\text { R. D. }=\frac{\text { Nitrogen in supernatant }-(\text { Blank I }+ \text { Blank II })}{\text { Nitrogen in the sample before digestion }} \times 100
$$

Nitrogen was measured by the Kjeldahl method. Blank I: \% TCA-soluble nitrogen Vol. 32, No. 1, 1986 
of pepsin-pancreatin solution. Blank II: \% TCA-soluble nitrogen of the sample incubated without pepsin-pancreatin solution.

\section{RESULTS AND DISCUSSION}

\section{Browning intensity of lysozyme-carbonyl reaction solutions}

Browning intensity of the reaction solutions of lysozyme with carbonyl compounds is shown in Fig. 2. After 10 days of reaction the browning intensity of the reaction solution was in the following order: diacetyl $>$ glyoxal $>$ methylglyoxal $>$ D-xylose $>$ methyl linoleate. These results showed that the reaction rate of dicarbonyl compounds are higher than those of xylose or methyl linoleate in the reaction with lysozyme. The extremely high reaction rate of diacetyl is to be noted, this tendency being similar to that of the case of amino acids or peptides in the reaction with $\alpha$-dicarbonyl compounds $(8)$.

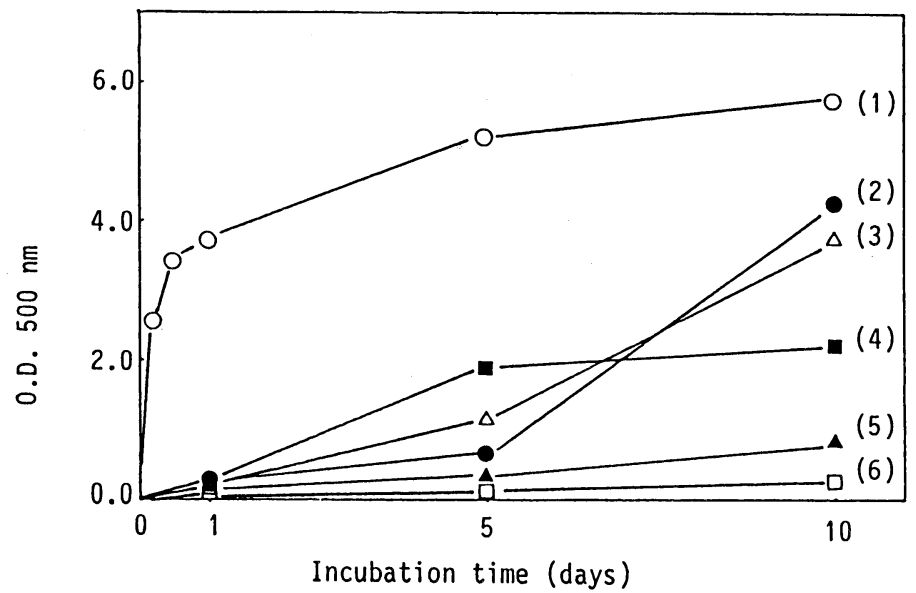

Fig. 2. Browning of lysozyme in the reaction with dicarbonyl compounds in aqueous system. Lysozyme $(0.7 \mathrm{~mm})$ was reacted with dicarbonyl compounds $(35 \mathrm{~mm})$ in phosphate buffer solution ( $\mathrm{pH} 6.0$ ) at $50^{\circ} \mathrm{C}$. (1), lysozyme+diacetyl; (2), lysozyme +glyoxal; (3), lysozyme + methylglyoxal; (4), lysozyme + D-xylose; (5), lysozyme + methyl linoleate; (6), control.

\section{Polymerization of lysozyme caused by carbonyl compounds}

Electrophoretograms of lysozyme incubated with various carbonyl compounds are shown in Fig. 3. Dicarbonyl compounds showed a higher rate of polymerization of lysozyme than methyl linoleate and xylose.

The amounts of monomer and oligomers of the reacted lysozymes measured by a densitometer at $565 \mathrm{~nm}$ are shown in Table 1 . After 1 day of reaction, in the case of diacetyl, only $41 \%$ of lysozyme remained as monomer while in the cases of glyoxal and methylglyoxal, $66 \%$ and $80 \%$ of lysozyme monomers remained 

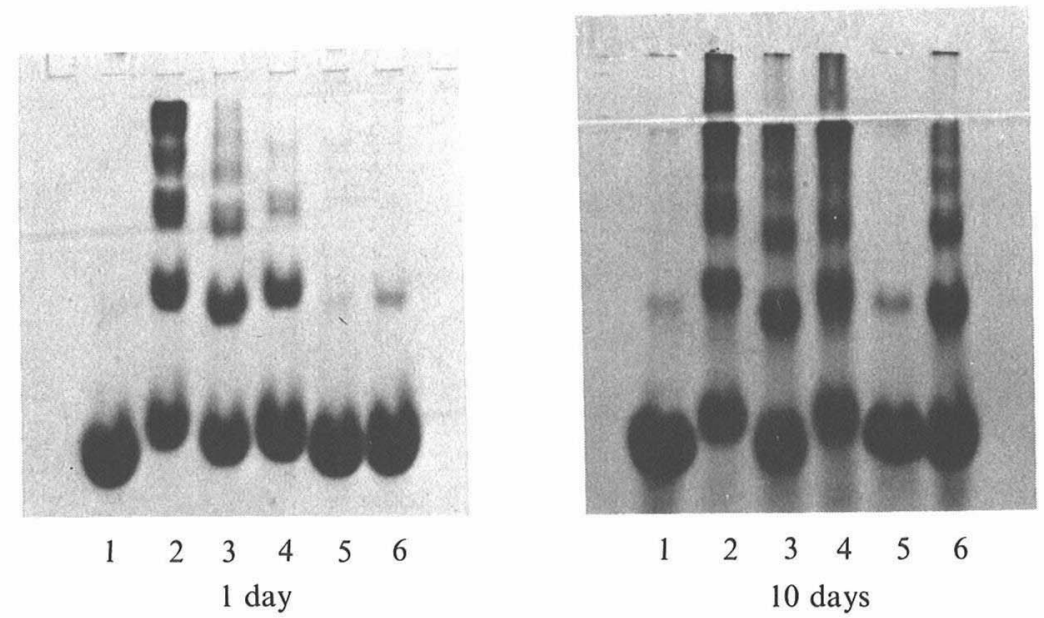

Fig. 3. Electrophoretic patterns of lysozyme in the reaction with carbonyl compounds at $50^{\circ} \mathrm{C}, \mathrm{pH} 6.0$ in aqueous system. 1, control; 2, lysozyme + diacetyl; 3, lysozyme + glyoxal; 4, lysozyme + methylglyoxal; 5, lysozyme + methyl linoleate; 6 , lysozyme +D-xylose. SDS-polyacrylamide gel electrophoresis was carried out with slab gel $(10 \%)$. The samples were dissolved in $1.7 \%$ SDS solutions containing $10 \% 2$ mercaptoethanol. Coomassie brilliant blue R-250 solution ( $0.1 \%$ ) was used for staining.

respectively. The polymerization of lysozyme due to these dicarbonyl compounds was observed to continue still up to 10 days.

On the other hand, in the case of xylose and methyl linoleate, almost all lysozymes remained as monomer after 1 day of reaction.

However, through 10 days of reaction, xylose converted about $30 \%$ of lysozyme into polymerized forms while methyl linoleate converted only $3 \%$ of lysozyme. Thus, it seemed that with the reaction conditions in this study, methyl linoleate was decomposed to only a small extent and polymerization also occurred to a minor degree.

The above results indicate that the polymerization process of protein through the reaction with dicarbonyl compounds is time-dependent, similarly to the reducing sugar-induced polymerization process of protein, although the rate of the former is much higher than that of the latter. The higher rate of polymerization induced by diacetyl seems to be related to its higher protein browning capability.

\section{Nitrogen content of browned lysozyme}

Nitrogen contents of browned lysozymes were measured by the Kjeldahl method and are shown in Table 2. In general, the nitrogen content of browned lysozyme decreased with the reaction time. After 5 days of reaction, the nitrogen content of the browned lysozyme incubated with dicarbonyl compounds decreased 


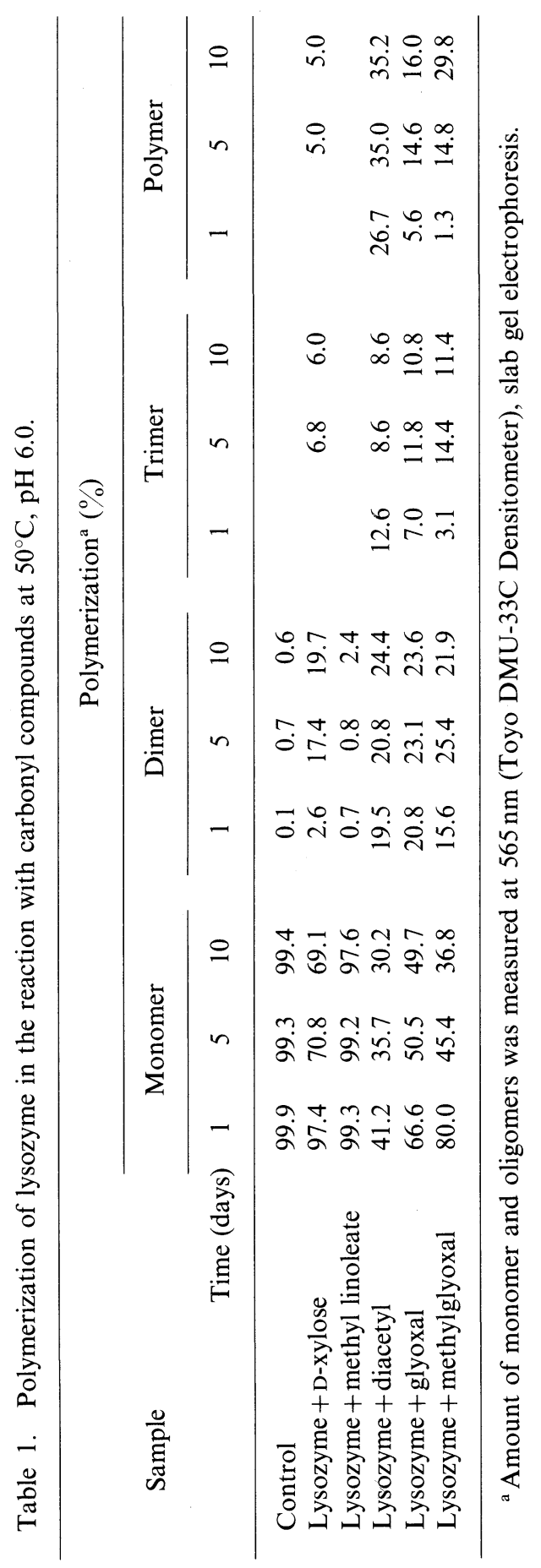


Table 2. Nitrogen content $(\mathrm{N} \mathrm{mg} / 100 \mathrm{mg})$ of browned lysozyme.

\begin{tabular}{|c|c|c|c|}
\hline \multirow{2}{*}{ Sample } & \multicolumn{3}{|c|}{ Reaction time } \\
\hline & 0 day & 5 days & 10 days \\
\hline Unheated lysozyme & 17.26 & & \\
\hline Control & & 16.26 & 16.93 \\
\hline Lysozyme + D-xylose & & 17.10 & $16.39(3.2 \%)^{\mathrm{a}}$ \\
\hline Lysozyme + methyl linoleate & & 16.40 & $16.32(3.6)$ \\
\hline Lysozyme + diacetyl & & $14.02(13.8 \%)$ & $12.70(25.0 \quad)$ \\
\hline Lysozyme + glyoxal & & $13.35(17.9 \quad)$ & $13.49(20.3 \quad)$ \\
\hline Lysozyme + methylglyoxal . & & $13.04(19.8 \quad)$ & $12.78(24.5)$ \\
\hline
\end{tabular}

${ }^{\mathrm{a}}$ Decreasing percentage (in comparison with control).

to $76-80 \%$ of the value of the control lysozyme. After 10 days of reaction the value decreased by $20-25 \%$, while that of the browned lysozyme incubated with D-xylose or methyl linoleate decreased by only $3-4 \%$. It is known that when protein is incubated with the reducing sugar D-glucose in an aqueous solution, amino acids and oligopeptides are released from the protein (14). These factors may play a role in the decreased nitrogen content of browned lysozyme. Moreover, Clark and Tannenbaum (15a) reported that the $\mathrm{C} / \mathrm{N}$ ratio increased in the brown pigment isolated after protease (pronase) digestion of casein incubated with glucose at $55^{\circ} \mathrm{C}$ and $75 \%$ relative humidity. We also observed the increase in the $\mathrm{C} / \mathrm{N}$ ratio of lysozyme during incubation with glucose in the solid state $(15 b)$. Thus, the incorporation of carbonyl compounds into the lysozyme molecule is probably one of the causes of the phenomenon of decreased nitrogen per unit weight of browned lysozyme.

\section{Loss of amino acids in browned lysozyme}

Damage of amino acid residues of lysozyme in the reaction with carbonyl compounds is shown in Table 3 . There was a large decrease in the amount of lysine, tryptophan and arginine.

After 10 days of reaction, methylglyoxal caused the loss of $48 \%$ lysine, $46 \%$ tryptophan and $87 \%$ arginine, and glyoxal caused the loss of $70 \%$ lysine, $12 \%$ tryptophan and $98 \%$ arginine. Diacetyl caused the loss of $26 \%$ lysine, $38 \%$ tryptophan and $94 \%$ arginine. Xylose caused the loss of $27 \%$ lysine, $23 \%$ arginine but tryptophan was unaffected. Methyl linoleate caused the loss of only tryptophan $(48 \%)$, but lysine and arginine were scarcely affected. Desai and Tappel(16) reported that in the reaction of cytochrome $c$ with peroxidized lipids, histidine, serine, proline and arginine were most labile to peroxidative damage. Leake and Karel (17) also reported that tryptophan was lost to a great extent in the reaction of lysozyme with methyl linoleate, and suggested that tryptophan radicals were the 


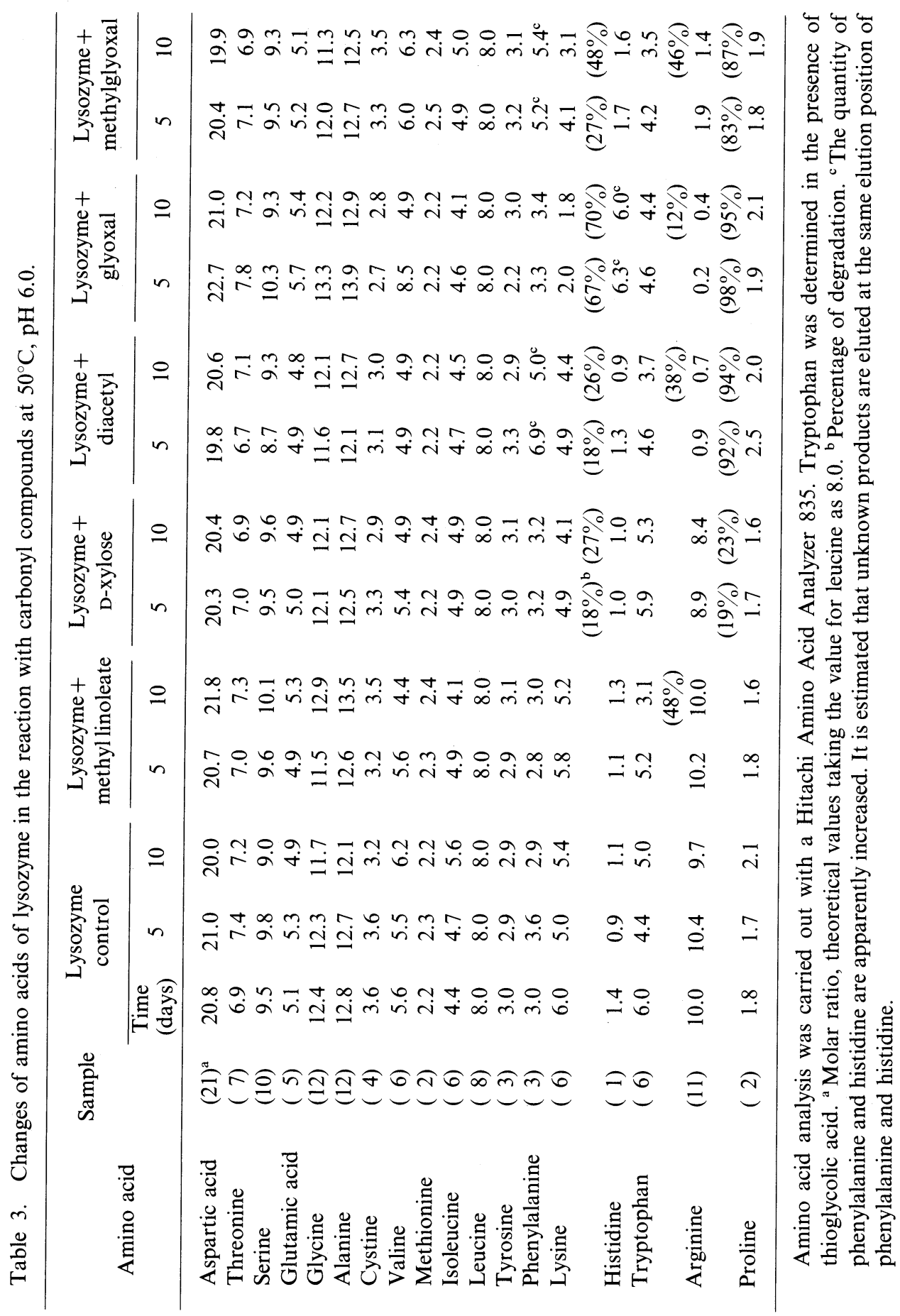


major ones formed in lysozyme. Kanazawa et al. (18) also reported that in the reaction of lysozyme with linoleic acid, the products of degradation of this acid, i.e., linoleic acid hydroperoxide, secondary degradation products, final products, benzoylperoxide and malonaldehyde particularly attacked tryptophan, lysine and histidine residues. They also proved that tryptophan was mostly destroyed by secondary products and benzoylperoxide. In this study, a similar phenomenon might have occurred in the reaction of lysozyme with methyl linoleate.

Furthermore, the present result that methyl linoleate shows a low rate of browning and polymerization of lysozyme in spite of its high ability to degrade tryptophan residues suggests that dicarbonyl compounds do not have a major role in the damage of protein caused by oxidizing linoleate and that tryptophan residues have a low involvement in the polymerization and browning of protein. Thus, it seems most propable that lysine and arginine residues are responsible for the crosslinking of lysozyme molecules leading to polymerization.

Since lysine and tryptophan are both essential amino acids from the nutritional point of view, it may be concluded that in the reaction of lysozyme with $\alpha$ dicarbonyl compounds, glyoxal and methylglyoxal induced much more nutritional damage to the protein than did diacetyl.

Another aspect of interest shown in Table 3 is the apparent increase of the quantity of phenylalanine and histidine of lysozyme in the reaction with dicarbonyl compounds. In the reaction of lysozyme with glucose in the dry state $(10 a)$, a rise in phenylalanine content was observed. This has been explained by the fact that the lysine and arginine residues modified by the dicarbonyl compounds are eluted at the same elution position as phenylalanine or histidine on the amino acid analysis of $6 \mathrm{~N}$ $\mathrm{HCl}$-hydrolysates (unpublished).

\section{Relative digestibility of browned lysozyme}

The relative digestibility of browned lysozyme after incubation with pepsinpancreatin is shown in Table 4. After 5 days of reaction with glyoxal, the relative digestibility of lysozyme decreased to about $80 \%$, and after 10 days to about $70 \%$. In the case of the lysozyme-xylose reaction, the relative digestibility of xylose reacted with lysozyme was higher than that of heated lysozyme. It seems that lysozyme reacted with xylose in the early stage of the reaction is more readily hydrolyzed by protease than is heated lysozyme. This result is in accordance with that of Kato et al. (19) from the reaction of ovalbumin with glucose, that is, the level of tryptic hydrolysis of a stored preheat-treated ovalbumin-glucose complex at $50^{\circ} \mathrm{C}$ and $65 \%$ relative humidity was higher than that of preheat-treated ovalbumin and unstored preheat-treated ovalbumin-glucose complex.

After 10 days of reaction with carbonyl compounds, it was observed that the relative digestibility of browned lysozyme reacted with dicarbonyl was lower than that of lysozyme reacted with methyl linoleate or xylose. Therefore, from the digestive aspect, the dicarbonyl compounds, especially methylglyoxal and glyoxal, lowered the digestibility of lysozyme much more than methyl linoleate and xylose. 
Table 4. Relative digestibility (in vitro) of lysozyme reacted with carbonyl compounds at $50^{\circ} \mathrm{C}, \mathrm{pH} 6.0$.

\begin{tabular}{|c|c|c|}
\hline \multirow{3}{*}{ Sample } & \multicolumn{2}{|c|}{ Relative digestibility* $(\%)$} \\
\hline & \multicolumn{2}{|c|}{ Reaction time } \\
\hline & 5 days & 10 days \\
\hline Control & $92.8(96.4)^{* *}$ & 96.7 \\
\hline Lysozyme + D-xylose & 95.4 & 96.6 \\
\hline Lysozyme + methyl linoleate & 95.0 & 94.2 \\
\hline Lysozyme + diacetyl & 85.6 & 88.8 \\
\hline Lysozyme + glyoxal & 80.9 & 74.3 \\
\hline Lysozyme + methylglyoxal & 86.5 & 67.0 \\
\hline
\end{tabular}

${ }^{*}$ Relative digestibility $(\%)=\frac{\mathrm{N} \text { in supernatant }-\left(\text { Blank } \mathrm{I}^{\mathrm{a})}+\mathrm{Blank}^{\mathrm{b}}{ }^{\mathrm{b})}\right)}{\mathrm{N} \text { in total sample }} \times 100$

a) Blank I, \% TCA-soluble N of pepsin-pancreatin solution; ${ }^{\text {b) }}$ Blank II, \% TCA-soluble $\mathrm{N}$ of sample without pepsin-pancreatin treatment.

** Relative digestibility of unheated lysozyme.

In general, from Tables 3 and 4, it can be estimated that the relative digestibility of browned lysozyme decreased with increasing degree of polymerization. When polymerization is increased, the total loss of amino acids is also increased. However, no correlation of relative digestibility or degree of polymerization with the loss of each amino acid, i.e., lysine, tryptophan and arginine was found. From the nutritional point of view, this problem must be resolved by future experiments in vivo.

\section{REFERENCES}

1) Hodge, J. E. (1967): Chemistry and Physiology of Flavor, ed. by Schultz, H. W., Day, E. A., and Libbey, the AVI Publishing Co., Inc., pp. 472.

2) Heyns, K., Stute, R., and paulsen, H. (1966): Braunungsreaktionen und fragmentierungen von kohlenhydraten. Carbohydrate Res., 2, 132-149.

3) Cobb, W. Y., and Day, E. A. (1965): Characterization of some dicarbonyls from autoxidized methyl linoleate. J. Am. Oil Chem. Soc., 42, 420-422.

4) Seals, R. G., and Hammond, E. G. (1970): Some carbonyl flavor compounds of oxidized soybean and linseed oil. J. Am. Oil Chem. Soc., 47, 278-280.

5) Rizzi, G. P. (1969): Formation of tetramethylpyrazine and 2-isopropyl-4,5-dimethyl3-oxazoline in the Strecker degradation of DL-valine with 2,3-butanedione. J. Org. Chem., 34, 2002-2004.

6) Wang, P. S., Kato, H., and Fujimaki, M. (1969): Studies on flavor components of roasted barley. Agric. Biol. Chem., 33, 1775-1781.

7) Nguyen, V. C., Kurata, T., and Fujimaki, M. (1973): Formation of $N$-carboxymethyl 
amino acid from the reaction of amino acid with glyoxal. Agric. Biol. Chem., 37, 2209-2210.

8) Nguyen, V. C., Kurata, T., and Fujimaki, M. (1973): Studies on the reaction of dipeptides with glyoxal. Agric. Biol. Chem., 37, 327-334.

9) Nguyen, V. C., Kurata, T., and Fujimaki, M. (1973): Formation of $N[2$ (3-alkylpyrazin2-on-1-yl)]-amino acid or peptide on heating tri- or tetrapeptides with glyoxal. Agric. Biol. Chem., 37, 1613-1618.

10a) Okitani, A., Cho, R. K., and Kato, H. (1984): Polymerization of lysozyme and impairment of its amino acids residues caused by reaction with glucose. Agric. Biol. Chem., 48, 1801-1808.

10b) Cho, R. K., Okitani, A., and Kato, H. (1984): Mechanism of reducing sugar-induced polymerization of protein. Proc. Annual Meeting of Agric. Chem. Soc. Jpn., Tokyo, p. 117.

11) Weber, K., and Osborn, M. (1969): The reliability of molecular weight determinations by dodecyl-sulfate-polyacrylamide gel electrophoresis. J. Biol. Chem., 244, 4406-4412.

12) Matsubara, H., and Sasaki, R. M. (1969): High recovery of tryptophan from acid hydrolysates of proteins. Biochem. Biophys. Res. Commun., 35, 175-181.

13) Matoba, T., Yoshida, H., and Yonezawa, D. (1981): Simplified nutritional evaluations of proteins of some soy products based on in vitro digestibility. Nippon Eiyō Shokuryō Gakkaishi (J. Jpn. Soc. Nutr. Food Sci.), 34, 415-421.

14) Kato, H., Matsumura, M., and Hayase, F. (1981): Chemical change in casein heated with and without D-glucose in the powdered state or in an aqueous solution. Food Chem., 7, 159-168.

15a) Clark, A., and Tannenbaum, S. R. (1970): Isolation and characterization of pigments from protein-carbonyl browning systems. J. Agric. Food Chem., 18, 891-894.

15b) Cho, R. K., Okitani, A., and Kato, H. (1984): Chemical properties and polymerizing ability of the lysozyme monomer isolated after storage with glucose. Agric. Biol. Chem., 48, 3081 .

16) Desai, I. D., and Tappel, A. L. (1963): Damage to proteins by peroxidized lipids. $J$. Lipid Res., 4, 204-207.

17) Leake, L., and Karel, M. (1982): Polymerization and denaturation of lysozyme exposed to peroxidizing lipids. J. Food Sci., 47, 737-739.

18) Kanazawa, K., Danno, G., and Natake, M. (1975): Lysozyme damage caused by secondary degradation products during the autoxidation process of linoleic acid. $J$. Nutr. Sci. Vitaminol., 21, 373-382.

19) Kato, Y., Watanabe, K., Nakamura, R., and Sato, Y. (1983): Effect of pre-heattreatment on tryptic hydrolysis of Maillard reacted ovalbumin. J. Agric. Food Chem., 31, 437-441. 